\title{
PILOT STUDY OF VISIBILITY LEVEL WITH THE USE OF A DRIVING SIMULATOR
}

\author{
M. ZALESINSKA \\ Institute of Electrical Engineering and Electronics, \\ Poznan University of Technology, Poland
}

\begin{abstract}
The visibility of obstacles in the road is one of the decisive factors impacting road safety. The difficulty in spotting an obstacle in the road and in evaluating its effect on driving depends on such factors as: lighting conditions on the road and its vicinity, the obstacle's geometric and photometric properties, conditions of observation of objects and the driver's psychomotor function. The obstacle visibility tests were performed using a car driving simulator built in the laboratory of the Poznan University of Technology. The article describes the testing procedure and the visibility level tests results obtained in the driving simulator. The analysis of the obtained results has been performed and the possible use of a driving simulator to test the visibility of obstacles and the driver's visual performance has been verified.

Keywords: Driving simulator, road lighting, visibility level.
\end{abstract}

\section{INTRODUCTION}

Correctly designed and executed stationary road lighting should provide the required sight reliability to all road users. It is considered that normative requirements [1] for the luminance of a medium sized road (illuminance) regarding general and longitudinal uniformity ratio of luminance and also the limiting of glare and correct sight guiding, allow obtaining correct visual performance and comfort of the driver from the point of view of lighting conditions. However, tests (Golik \& Gorczewska [2]) indicate that despite meeting normative requirements, it is not always guaranteed that the obstacle will be noticed on a road with stationary lighting.

The level of difficulty when spotting an obstacle in the road mainly depends on illumination conditions in the road, the geometric and photometric properties of the obstacle and the driver's psychomotor functions. In city traffic, an additional factor related to the obstacle observation conditions also plays a role. It is usually more difficult to drive a vehicle in the city than it is in a straight section of a road outside populated areas. This increased difficulty is related to the need to constantly select the right route, change lanes and monitor the positions of other road users. Additionally, there is differing complexity of the driver's field of vision. There may be objects of various luminance attracting and distracting the driver's attention, such as shop windows, conventional billboards and LED billboards. Excessive luminance of surfaces in the road's vicinity, especially at night, may lead to reduced visual performance of drivers, and consequently impact the visibility of obstacles on the road and its vicinity. Special hazard comes from LED billboards that, apart from very high luminance levels, also feature large surfaces, high luminance contrast and colour contrast, and whose content (animated or video) is very dynamic (Domke \& others [3], Zalesinska \& others [4]). The knowledge of the impact of observation conditions on the visibility of obstacles on the road will allow for the optimization of lighting parameters related to obstacle visibility levels and the effective use of energy for lighting purposes.

\section{VISIBILITY LEVEL}

The International Commission on Illumination (CIE) introduced in 1972, the definition of visibility level (VL), being the relation of the current contrast of a reference object (a disc of angular diameter 
of 4 minutes) to background to the object's threshold contrast in threshold conditions, with the same background luminance [5].

$$
V L=\frac{C}{C_{t h}}=\frac{\Delta L}{\Delta L_{t h}}
$$

where: $C$ - the real contrast between the object and its background,

$C_{t h}$ - the contrast's threshold value,

$\Delta L$ - the real difference of the luminance of the object and the background,

$\Delta L_{t h}$ - the threshold value of the difference in luminance.

The direct application of formula (1) to calculate the visibility level on the road is virtually impossible, as the driver's visual task differs significantly from the relative task recommended by CIE [5] either in terms of the size and shape of objects used in the experiment, or in terms of criteria used for measuring the driver's performance. It is therefore impossible to determine the contrast's threshold values or luminance difference.

Adrian's (Adrian [6]) research at the end of 1980's finally led to a calculation model of Visibility Level on the road. Currently, Adrian's formula is the basis for Small Target Visibility (STV) criterion [7]. Apart from illuminance and luminance, STV is the third criterion employed when designing road lighting in USA. In Europe countries, Visibility criterion is still investigated as a new concept.

Adrian's visibility level calculation model (Adrian [6]) based on two laws: Ricc's and Weber's. For purposes of calculation of $\Delta \mathrm{L}_{\text {th }}$ Adrian introduced two auxiliary functions, $\Phi$ - light stream function responsible for perception and related to Ricc's law, and L — luminance function resulting from Weber's law. Moreover, the following additional factors directly influencing the visibility have been taken into account in the mathematical description of the threshold luminance of the object and its background as proposed by Adrian: the observer's age, by applying the factor AF, obstacle observation time - the factor TF and contrast polarization - the factor $\mathrm{F}_{\mathrm{CP}}$.

$$
\Delta L_{t h}=2.6\left(\frac{\Phi^{1 / 2}}{a}+L^{1 / 2}\right)^{2} \cdot A F \cdot T F \cdot F_{C P}
$$

where: $\alpha$ - angular size of the object on the road

For background luminance of $\mathrm{L}_{\mathrm{b}} \geq 0.6 \mathrm{~cd} / \mathrm{m}^{2}$, functions of the luminous flux $\Phi$ and luminance $\mathrm{L}$ describe eqns (3) and (4):

$$
\begin{gathered}
\Phi^{1 / 2}=\log \left(4.1925 L_{b}^{0.1556}\right)+0.1684 L_{b}^{0.5867} \\
L^{1 / 2}=0.05946 L_{b}^{0.0 .466}
\end{gathered}
$$

Factors AF, TF, FCP describe eqns (5), (6), (7)

$$
\begin{aligned}
& A F=\frac{(a g e-19)^{2}}{2160}+0,99 \\
& T F=\Delta L_{t=2 s} \frac{a\left(a, L_{b}\right)+t}{t}
\end{aligned}
$$


where: $\mathrm{a}$ - factor depending on the angular size of object $\alpha$ and background luminance $\mathrm{L}_{\mathrm{b}}$,

$\Delta \mathrm{L}_{\mathrm{t}=2 \mathrm{~s}}$ - difference between the luminance of the object and the background, for observation time of $2 \mathrm{~s}$.

$$
F_{C P}=1-\frac{m \cdot a^{-\beta}}{2.4 \cdot \Delta L_{p o s, t=2 s}}
$$

where: $\mathrm{m}, \beta$ - factors depending on background luminance,

$\Delta \mathrm{L}_{\text {pos, } t=2 \mathrm{~s}}$ - difference between the luminance of the object and the background for positive polarization of the contrast and for observation time of $2 \mathrm{~s}$.

The impact of disability glare caused by the road lighting system is taken into account in the form of veiling luminance $\mathrm{L}_{\mathrm{v}}$ added to background luminance. The veiling luminance is determined on the basis of the classic Stiles-Holladay formula [9]:

$$
L_{V}=k_{V} \sum_{i=1}^{n} \frac{E_{\text {glare }_{i}}}{\Theta_{i}^{2}}
$$

where: $\mathrm{k}_{\mathrm{v}}$ - factor depending on the observer's age,

$\mathrm{E}_{\text {glarei }}$ - illuminance generated by the ith luminaire in plane perpendicular to the line of sight and at the observer eyes' level,

$\Theta_{\mathrm{i}}$ - the angle between the line of sight and the line crossing the light center of the ith luminaire, $1.5^{\circ} \leq \Theta \leq 60^{\circ}$.

Adrian's model and Small Target Visibility (STV) are used simplifications and assumptions. The road section considered during the calculation is free from other traffic participants and vehicles approach from the opposite direction, hence no glare caused by headlights of these vehicles. The driver's visual task is simple and consists in spotting an object in a specified location, aligned directly with the driver's eyesight. Under real conditions, the complexity and dynamics, combined with other traffic participants, significantly limit the visibility of obstacles on the road.

\section{DRIVING SIMULATOR BUILT IN THE LABORATORY OF THE POZNAN UNIVERSITY OF TECHNOLOGY}

\subsection{Description of the driving simulator}

In order to perform the visibility tests for various driving difficulty levels and for different field of vision complexity levels as well as to perform eye-sight tasks, a passenger car driving simulator has been used, built to perform research on the impact of large electronic billboards on the visual capability of drivers, financed by the Ministry of Science and Higher Education in the years 2011-2013.

According to the classification found in literature (Weir [9]), the simulator belongs to medium class static group. The major components of the simulator include: the vehicle's cabin, the display system, the screen and the control system. Additionally, the laboratory test station contains a real electronic billboard which allows testing of the driver's visual performance in different levels of field of vision complexity.

The vehicle's cabin was built based on Fiat Seicento. It has a classic dashboard including buttons, radio, working ventilation system and a working speedometer indicating the current speed. The 

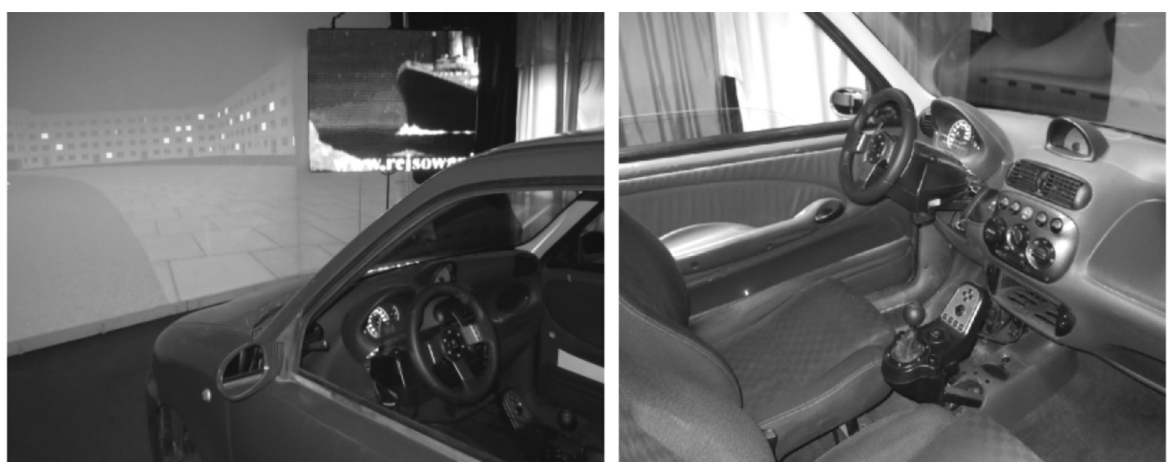

Figure 1: View of the car simulator.

vehicle is equipped with a manual gearbox and acceleration, brake and clutch pedals. While driving, the driver is able to perform all operations that are required i.e. changing the direction of travel by moving the steering wheel, changing gear by pressing the clutch pedal and changing gear using the shift stick, accelerating and braking by pressing the acceleration and brake pedals. The changes in driving speed and engine operation are recreated by changing acoustic stimuli reaching the driver from speakers located in place of the engine. Additionally, the vibration of the steering wheel and dashboard related to the running engine, have been recreated. It is also possible to listen to the radio while driving in the simulator. The external appearance of the cabin and its position in the laboratory as well as the interior view are presented in Fig. 1.

While driving, the simulation image is displayed on a $5.3 \mathrm{~m} \times 2.9 \mathrm{~m}$ screen, a section of the shorter wall of the laboratory's room. The angle of view of the displayed picture is $67.5^{\circ}$ horizontally and $40.8^{\circ}$ vertically, from the driver's position. The picture is displayed using two multimedia projectors. The main projector displays the road observed by the tested person between the angles $26.7^{\circ}$ to the left and $25.8^{\circ}$ to the right of the observer's optical axis. The additional projector supplements the picture below the electronic billboard. The use of such arrangement allows to extend the observed picture generated by the main projector by about $15^{\circ}$ and has considerably facilitated right turns.

Due to the limited ability of the projector to recreate luminance exceeding $115 \mathrm{~cd} / \mathrm{m}^{2}$, the luminance of luminaires causing glare has been simulated using an electroluminescent diode. In the assumed geometry of displaying the road's image, the diode generated in the observer's eye has illuminance of $2.1 \mathrm{~lx}$. This value has been selected so that in accordance with the requirements of the standard [1] for the assumed lighting class ME3a, the threshold value of TI does not exceed $15 \%$. The appearance and positioning of the substitute glare source in the car cabin has been presented in Fig. 2.

The simulator's software allows creation of various routes through the virtual city. It is possible to create a route including straight sections, corners, T-intersections in different building development conditions. It is possible to add obstacles, speed limits and markers, which are invisible to the driver, activating the billboard lights of different intensity along the route. Additionally, it is possible to enter and specify the number of vehicles travelling on the left (opposite) lane and pedestrians walking along the pavements (on the left and on the right side). All data obtained from the test run are stored in the so called event recorder.

During the construction of the laboratory station a simplifying assumption has been made regarding omitting the real luminance of car lights. It is assumed that additional traffic observers have been 


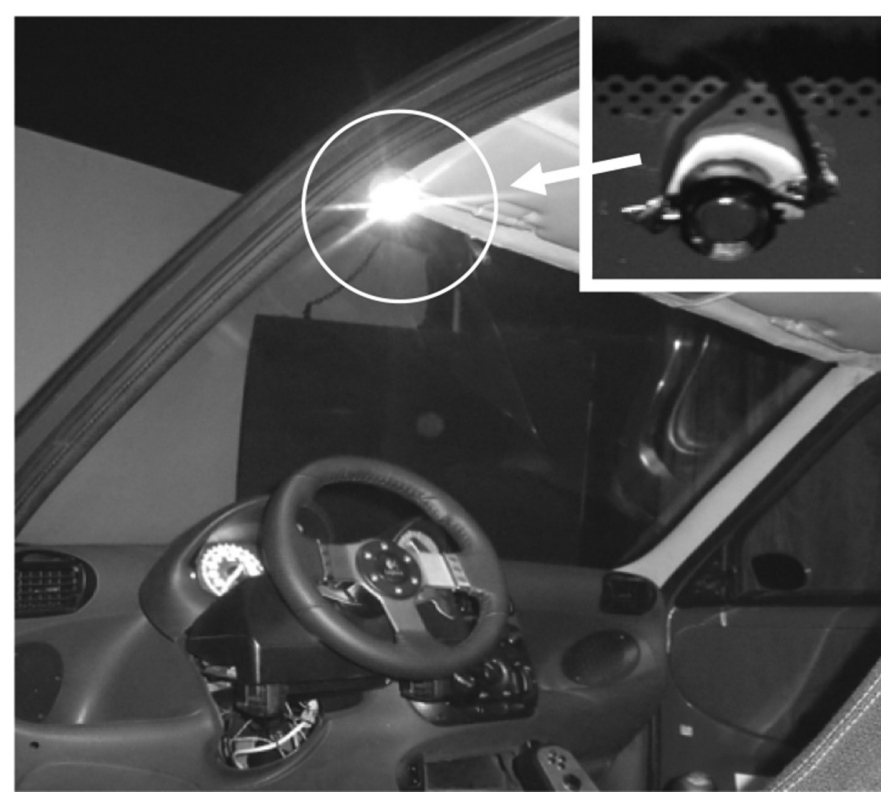

Figure 2: The substitute glare source in the car cabin.

included solely for the purpose of simulating the tasks directly related to driving a vehicle in an urban environment: the visual and the psychomotor tasks.

In order to improve the realism of travelling in an urban environment, the side walls are lit up. Electroluminescent diodes covered with a milky glass dissipating panel located behind a grey curtain were applied for this purpose. Using LEDs and controlling them allowed obtaining a constant value of average luminance of $4.5 \mathrm{~cd} / \mathrm{m}^{2}$ and a changing luminance simulating the movement of the vehicle in the environment (windows, shop windows) of $14 \mathrm{~cd} / \mathrm{m}^{2}$.

\subsection{Calibration of the driving simulator}

The calibration of the driving simulator has been performed based on field research of luminance conditions found in the field of view. The average values of luminance of the roadway, pavement, building elevations, illuminated windows, shop windows, lighting posts, paint stripes on the roadway and the horizon were reproduced in the displayed images of the town. The calibration of the road simulator in terms of luminance displayed in the observer's field of view was done by changing (in the settings menu) coefficients impacting the luminance of specific elements of the road simulator. The detailed description of field research and simulator calibration may be found in the literature (Zalesinska \& Wandachowicz [10], Zalesinska \& Wandachowicz [11]).

An example of distribution of luminance in the displayed road and in its direct vicinity is presented in Fig. 3.

In laboratory conditions, the luminance of the road and of its vicinity and the contrast of all objects against the background are not derived from the road's fixed lighting; instead, they are digitally simulated and displayed by a projector on a screen with fixed reflection coefficient. This means that the given constant parameters of the color of the displayed obstacle, regardless of its location in 


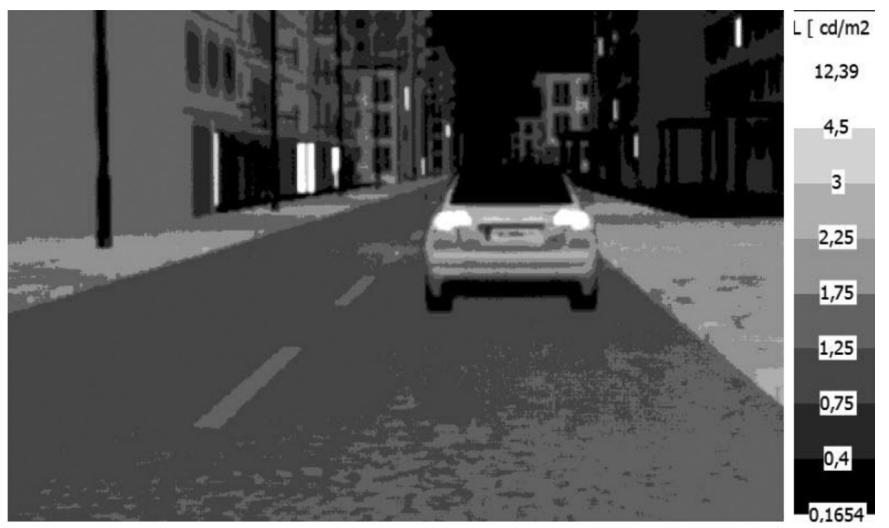

Figure 3: Distribution of luminance on the projected image.

the road, the obstacle will always have the same luminance. The designed and built laboratory test bed allows us to change the luminance of a standard obstacle in very wide range, actually much wider than for luminance obtained in real life conditions. Consequently, it was possible to simulate both a negative and positive contrast of the obstacle against the background.

The built and calibrated laboratory test bed was used for the purpose of conducting pilot tests to determine the driver's reaction time to sudden emergence of an obstacle in the road, and further to determine the level of visibility of such an obstacle in various lighting conditions.

\section{PILOT TESTS OF VISIBILITY LEVEL WITH THE APPLICATION OF THE DRIVING SIMULATOR}

\subsection{Experiment preparations}

During the experiment, the reaction time of participants, to the appearance of a standard obstacle (a $0.2 \mathrm{~m}$ square [5]) on the road with average luminance of $1.5 \mathrm{~cd} / \mathrm{m}^{2}$ was measured. The reaction time of the observers was measured between the appearance of the obstacle on the road to their reaction to this event. Actions such as pressing the brake pedal or a quick movement of the steering wheel to avoid the obstacle were considered reactions. The time was measured with $1 \mathrm{~ms}$ accuracy.

Obstacles of various luminance were used during the experiment which appeared on the road in locations with luminance higher than the average road luminance (under luminaires) and lower than the average luminance (between luminaires). The luminance of obstacles and the luminance of the environment have been selected so that the contrast between the obstacle and the background was always negative and assumed values of about $0.01,0.1,0.2$ and 0.4 . In order to unequivocally establish the observer's reaction time to the appearance of the obstacle on the road, it was assumed that the obstacle appears instantaneously.

Five routes in a virtual city were prepared to conduct the experiment. The first route was designed to help the observers familiarize themselves with the operation of the simulator and the appearance of obstacles on the road. The remaining routes were used to evaluate the observer's reaction time and the visibility of obstacles. The routes were designed to allow for analysis of the results considering the complexity of the task (simple task-observing the road and more complicated tasks-observing the roadside and searching for particular obstacles), complexity of the field of vision (just the 
obstacles, without billboards and obstacles appearing on the road while the LED billboards were lit) and driving difficulty (straight road, urban conditions with bends and intersections).

Because of the operating principle and resolution of the simulation, it was decided that during the pilot tests the obstacles would appear on the road at a distance of $24 \mathrm{~m}$ in front of the observer.

In order to eliminate the impact of the design of the route itself on the observer's reaction time, the routes were designed to have the same number of turns, intersections and straight sections projected exactly in the same order, but with different scenery (different appearance of buildings).

\subsection{Results and analysis}

Thirty-five volunteers, aged 20-50, participated in the pilot study. Every person was a holder of a driving license. Most of participants owned their driving license for no longer than 10 years. One person was a professional driver. Six of the tested persons failed to complete a full cycle of tests. The observers were diagnosed with symptoms of simulator sickness. The description of typical symptoms of simulator sickness is covered in literature (Draper [12]).

For every case visibility level value was determined based on average reaction times of observers and the procedure for determining visibility as described in literature [USA x]. For every contrast level a minimum and maximum reaction time was established for the simulated road events. Establishing the minimum time allowed to calculate the highest visibility level for the given contrast level. For longer reaction times, related to lower visual performance, visibility levels must take lower values.

The background luminance $\mathrm{L}_{\mathrm{b}}$ (used in Adrian' model) was determined as the average luminance of a square area constituting the background of the observed object (except for the area of the obstacle—see Fig. 4.), whose side was equal to 3 times of the dimension of the obstacle's side.

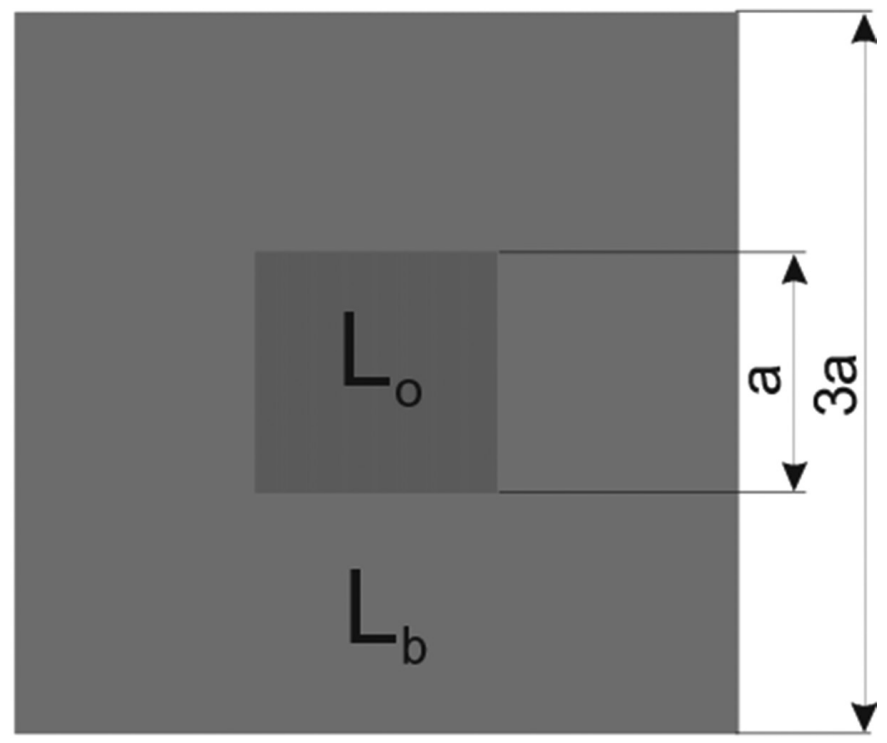

Figure 4: Imaging of surfaces taken into account to determine $\mathrm{L}_{\mathrm{o}}$ and $\mathrm{L}_{\mathrm{b}}$. 
Table 1: Average observer reaction time depending on luminance contrast between the obstacle and the background for different route complexities and visual tasks.

\begin{tabular}{|c|c|c|c|c|c|c|c|}
\hline \multirow[b]{3}{*}{$\mathrm{L}_{\mathrm{t}}\left[\mathrm{cd} / \mathrm{m}^{2}\right]$} & \multirow[b]{3}{*}{$\mathrm{L}_{\mathrm{b}}\left[\mathrm{cd} / \mathrm{m}^{2}\right]$} & \multirow[b]{3}{*}{$\mathrm{C}[-]$} & \multicolumn{5}{|c|}{ Average reaction times $\mathrm{t}_{\mathrm{ave}}[\mathrm{ms}]$} \\
\hline & & & \multicolumn{3}{|c|}{ simple task } & \multicolumn{2}{|c|}{ more complicated tasks } \\
\hline & & & straight road & urban area & $\begin{array}{l}\text { obstacles } \\
\text { with LED }\end{array}$ & $\begin{array}{c}\text { obstacles } \\
\text { without } \\
\text { LED }\end{array}$ & $\begin{array}{l}\text { obstacles } \\
\text { with LED }\end{array}$ \\
\hline 1,27 & 1,29 & 0,01 & 1501 & 1506 & 1581 & 1545 & 1626 \\
\hline 1,58 & 1,73 & 0,07 & 908 & 967 & 995 & 1133 & 1103 \\
\hline 1,03 & 1,29 & 0,22 & 840 & 887 & 863 & 894 & 874 \\
\hline 1,03 & 1,65 & 0,37 & 773 & 803 & 831 & 856 & 824 \\
\hline
\end{tabular}

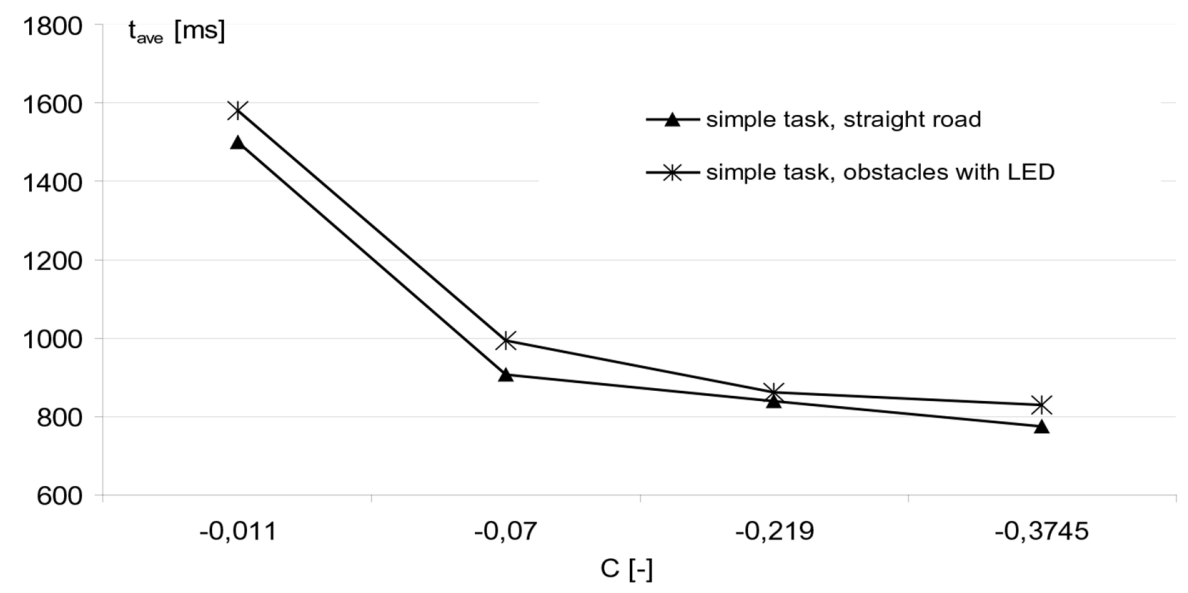

Figure 5: Average observer reaction times depending on luminance contrast.

The results of laboratory tests i.e. the average observer reaction times depending on the luminance contrast of the obstacle and the road section, driving in city streets with and without billboards lit up in the roadside are provided in Table 1 and Fig. 5.

The established VL values for the analyzed values are found in Table 2.

The conducted experiments confirmed a large influence of the obstacle and background luminance contrast on the drivers' visual performance. The minimum average reaction time of 1.5-1.6 s was achieved for the standard obstacle with a contrast against background of 0.01 . However, in numerous cases the observers failed to notice the obstacle and ran over it. Such cases were not taken into consideration when establishing the average reaction time. If such contrast value is used in further experiments, it would be required to increase the distance between the observer and the obstacle as it appears, thus increasing the time to notice the obstacle. At other contrast levels the reaction times were from, approximately, 1.1 to $0.77 \mathrm{~s}$. 
Table 2: Calculated visibility level values depending on luminance contrast between the obstacle and the background for different route complexities and visual tasks.

\begin{tabular}{|c|c|c|c|c|c|c|c|}
\hline \multirow[b]{3}{*}{$\mathrm{L}_{\mathrm{t}}\left[\mathrm{cd} / \mathrm{m}^{2}\right]$} & \multirow[b]{3}{*}{$\mathrm{L}_{\mathrm{b}}\left[\mathrm{cd} / \mathrm{m}^{2}\right]$} & \multirow[b]{3}{*}{$\mathrm{C}[-]$} & \multicolumn{5}{|c|}{ Average visibility level VL [-] } \\
\hline & & & \multicolumn{3}{|c|}{ simple task } & \multicolumn{2}{|c|}{ more complicated tasks } \\
\hline & & & straight road & urban area & $\begin{array}{l}\text { obstacles } \\
\text { with LED }\end{array}$ & $\begin{array}{c}\text { obstacles } \\
\text { without } \\
\text { LED }\end{array}$ & $\begin{array}{l}\text { obstacles } \\
\text { with LED }\end{array}$ \\
\hline 1,27 & 1,29 & 0,01 & 0,64 & 0,64 & 0,64 & 0,64 & 0,65 \\
\hline 1,58 & 1,73 & 0,07 & 4,5 & 4,5 & 4,4 & 4,3 & 4,7 \\
\hline 1,03 & 1,29 & 0,22 & 10,5 & 10,5 & 10,4 & 10,3 & 10,6 \\
\hline 1,03 & 1,65 & 0,37 & 20,1 & 20,1 & 19,7 & 19,5 & 20,4 \\
\hline
\end{tabular}

Following the analysis of the results regarding the complexity of the visual task, field of vision and vehicle driving difficulty, it may be assumed that it was the type of visual task that had the greatest impact on the visual performance. The differences in reaction times when observing the road and observing the road while looking for particular objects on the pavements amounted from a few to several percent. This fact was caused by a shorter time for road observation in case of the additional task.

The conducted research proved the impact of complexity of the field of view on visual performance. However, this impact is not as big as it was expected when the electronic billboard was near the road and acted as a source of glare and a distraction for the drivers. The differences in the obtained results varied between few and several percent. This may have been caused by the observers ignoring the billboard in the laboratory, while concentrating on reacting to the obstacle quickly. In a survey conducted after the experiment, most of the observers declared that they focused solely on the road and avoided observing the displayed advertisements. This means that in future research projects it would be required to induce the need to observe the advertisements displayed on the LED screen e.g. by including an additional task related to memorizing the contents while driving the simulator.

Based on the experiment results it was found that the driving task complexity level has the smallest impact on the visual performance among the analyzed factors. The differences between a straight section of the road and driving in a virtual city amounted to several percent. This fact might have been caused by the route design and locating the obstacles at straight road sections. Further experiments should include varying locations of obstacles i.e. in the corners, near intersections.

Based on the established average observers' reaction times, the average visibility of the objects on the road has been established. The obtained values allow concluding that the conducted experiments did not indicate an important impact of the complexity of the visual task, field of vision and driving difficulty even though these factors have an impact on the visual performance of the drivers. Considerable differences in visibility levels were the results of just the applied contrast values. This means that there is a need to make changes to the routes and the type of visual tasks for the observers.

\section{SUMMARY}

The use of a driving simulator in visibility level experiments allows approximating the external conditions to real conditions and allows recreating the effect of driving a vehicle in a city. Conduct- 
ing the experiments in the simulator allows eliminating numerous additional factors which may have an impact on the final result of the experiment that are found in real road conditions i.e. unpredictable behavior of other road users, different traffic loads or weather conditions. By using a sudden intrusion of an obstacle into the road it was also possible to test the driver's real reaction times to obstacles appearing on the road. The use of such solutions made it possible to eliminate the time related to making a decision on making any maneuver. It would be impossible to create such a situation in real conditions. The most important downside of laboratory experiments is conducting the measurements in conditions that are an approximation of real conditions i.e. the sensation of driving a car as well as the visual task-in reality, while driving through a city, the driver is rarely focused solely on the lane and often looks at advertisements, pedestrians and shop windows. In case of experiments conducted in a driving simulator, such situation must be enforced by assigning the observer an appropriate task e.g. searching for specific objects in the road vicinity. Therefore, experiments regarding the driver's visual performance in different conditions conducted using a driving simulator require the correct design of the routes and a proper selection of the visual task.

[1] PN -EN 13201: 2007: Road lighting.

\section{REFERENCES}

[2] Golik, W. \& Gorczewska, M., Luminance contrast in road lighting, $2^{\text {nd }}$ European Conference on Energy-Efficient Lighting, Arnhem, pp. 274-281, 1993.

[3] Domke, K., Wandachowicz, K., Zalesinska, M., Mroczkowska, S., \& Skrzypczak, P., Largesized digital billboards hazard. Design \& Nature and Ecodynamics, 7(4), pp. 367-380, 2012. doi: http://dx.doi.org/10.2495/dne-v7-n4-367-380

[4] Zalesińska, M., Wandachowicz, K., Domke, K., Skrzypczak, P. \& Mroczkowska, S., Research of the impact electronic billboards on the driver's visual performance, 12th European Lighting Conference, Krakow, pp. 323-328, 2013.

[5] CIE Publication No. 19:1979: A Unified Framework of Methods for Evaluating Visual Performance Aspects of Lighting.

[6] Adrian, W., Visibility of targets: model for calculation. Lighting Research and Technology 21(4), pp.181-188, 1989. doi: http://dx.doi.org/10.1177/096032718902100404

[7] Roadway lighting. ANSI/IESNA RP-8-00: American National Standard Practice for Broadway Lighting, Approval 2000.

[8] CIE Publication No. 146:2002: CIE equations for disability glare. doi: http://dx.doi. org/10.1002/col.10102

[9] Weir, D.H. \& Clark A.J., S survey of mid-level driving simulators. SAE Technical Paper 950172, 1995. doi: http://dx.doi.org/10.4271/950172

[10] Zalesińska, M. \& Wandachowicz, K., Examination of luminance distributions in the field of Vision of drivers in locations with LED billboards. Przeglad Elektrotechniczny (Electrotechnical Review), 8(2013), pp. 270-273, 2013.

[11] Zalesińska, M. \& Wandachowicz, K., Odtworzenie na stanowisku laboratoryjnym rozkładów luminancji występujących w polu widzenia kierowców (pl). Przeglad Elektrotechniczny (Electrotechnical Review), 1(2014), s. 277-280.

[12] Draper, M.H., Can your eyes make you sick?: Investigating the Relationship between the Vestibulo-ocular Reflex and Virtual Reality. Online http://www.hitl.washington.edu/ publications/r-96-3/ 